\title{
The Effect of Glucose Infusion on Myocardial Performance during Acute Hypoxia
}

\author{
Gerald B.H. Lewrs, M.B., F.F.A.R.A.C.S.* and \\ Kailash Prasad, M.D., Ph.D., F.I.C.A., F.A.G.C. ${ }^{\dagger}$
}

\section{SUMmaRY}

The effects of hypoxia with or without glucose infusion on the cardiac contractility, blood pressure, electrocardiogram, blood electrolytes (sodium and potassium), glucose, $\mathrm{pH}, \mathrm{Po}_{2}$, and $\mathrm{PcO}_{2}$ in anesthetized dogs were studied. Hypoxia was induced by ventilating the dogs with reduced oxygen $(10 \%)$ in the inspired air. Hypoxia produced a decrease in the cardiac contractility and blood pressure, and an increase in the heart rate and central venous pressure. It produced a decrease in the blood $\mathrm{pH}, \mathrm{PO}_{2}$, and $\mathrm{PCO}_{2}$, and an increase in the blood glucose and potassium. Glucose infusion during hypoxia delayed the rate of decrease in the contractility and blood pressure significantly. The time for decrease in the contractility to 45 to $50 \%$ was increased by $67 \%$. Glucose infusion prevented the loss of potassium from the cell. Glucose infusion however was unable to correct acidosis. These results indicate that glucose infusion during hypoxia might prevent or delay the deterioration of myocardial function.

\section{Additional Indexing Words:}

Cardiac contractility Blood pressure Electrocardiogram

Electrolyte Glucose infusion Acidosis

$7 H E$ anesthesiologist is confronted with patients in the operating room

1 and elsewhere who risk an episode of acute hypoxia from a variety of causes. Some patients with cardiac or pulmonary disease as well as those with multiple trauma already have a critical reduction of myocardial performance and tolerate hypoxia poorly.

Conversion of cardiac metabolism from aerobic to anaerobic pathways during hypoxia-the Pasteur effect-is accompanied by a great loss of efficiency. Whereas approximately $36 \mathrm{M}$ of adenosine triphosphate (ATP) are formed from the aerobic metabolism of $1 \mathrm{M}$ of glucose, only $2 \mathrm{M}$ of ATP

From the Departments of Anaesthesia and Physiology, College of Medicine, University of Saskatchewan, Saskatoon, Saskatchewan, Canada.

Address for reprints: Dr. K. Prasad, Dept. of Physiology, College of Medicine, University of Saskatchewan, Saskatoon, Sask. S7N OWO, Canada.

* Assistant Professor of Anaesthesia.

+ Professor of Physiology.

Received for publication March 29, 1976. 
are available from its glycolysis. Such a drastic reduction in available ATP does not meet the energy demands of contractile myocardium. ${ }^{11,2)}$ During anoxia augmented glucose transport into the cell and increased glycogenolysis make glucose available for glycolysis ${ }^{3)}$ but the uptake of glucose in the heart is a function of extracellular glucose. ${ }^{4}$

Anoxia has been reported to produce a shortening of the action potential duration (APD) and a decrease in the force of contraction of the guinea pig $^{5,6)}$ and human heart. ${ }^{\text {?-10) }}$ Glucose not only prevents but also abolishes the effects of anoxia on the APD and contraction of human papillary muscle obtained at open heart surgery. These effects of glucose are concentration dependent. ${ }^{7), 10)}$ Also, certain enzymes of the glycolytic pathway of glucose metabolism are stimulated during anoxia.11) These factors may lead to production of enough energy to maintain APD by decreasing the efflux of potassium and to partially maintain contraction during anoxia, provided that enough glucose is present in the extracellular fluid. ${ }^{5-10)}$

During surgery infusion of $0.9 \%$ sodium chloride solution at $7 \mathrm{ml} / \mathrm{Kg} / \mathrm{hr}$ blood glucose levels are maintained within normal limits with halothane anesthesia. Dextrose $5 \%$ in water infused at the same rate under similar circumstances raiscs the blood sugar level to $200-300 \mathrm{mg} \%$ within half an hour (unpublished observation).

The present study was undertaken, therefore, to determine the effect of glucose infusion on myocardial performance during acute hypoxia.

\section{Materials and Methods}

Dogs of either sex weighing 10 to $15 \mathrm{Kg}$ were anesthetized with pentobarbital $(35 \mathrm{mg} / \mathrm{Kg})$ intravenously. The trachea was cannulated. The dogs were ventilated initially with $60 \%$ oxygen in nitrogen using a Harvard respiratory pump with a volume of $20 \mathrm{ml} / \mathrm{Kg}$ and respiratory rate of $15-20 / \mathrm{min}$. A Beckman oxygen analyzer was used to determine the inspired oxygen percentage. The methods of recording electrocardiogram and blood pressure were the same as used by Prasad and DeSousa. ${ }^{12)}$ The aortic blood pressure was recorded by a catheter placed in the aorta through the femoral artery using a microdot blood pressure transducer (Model MS-5D) attached to a pressure coupler (Type 9853A) in a Beckman recorder. A femoral vein was cannulated to administer glucose or water. Electrocardiograms (ECG) from standard limb lead II were recorded.

The left ventricular contractility was measured by the method used by Prasad. ${ }^{13)}$ The chest was opened through the left fifth intercostal space and the heart was exposed. The pericardium was removed. A Walton Brodie strain gauge arch was sutured to the left ventricle and the contractility was recorded on the Beckman recorder through a force displacement coupler. The contractile force was not calibrated in absolute terms but was assessed in terms of millimeters of deflection. 
A catheter was positioned in the right atrium through the external jugular vein to monitor right atrial pressure. Arterial blood pressure, electrocardiogram, central venous pressure, and left ventricular contractility were monitored simultaneously on the Beckman recorder.

Blood samples were taken for determination of arterial $\mathrm{PaO}_{2}, \mathrm{PaCO}_{2}, \mathrm{pH}$, and percentage saturation analysis and at the same time serum potassium and sodium as well as blood glucose levels were measured. Blood gas analysis was done by the usual method using Instrumentation Laboratory Inc Model $113 \mathrm{pH} /$ gas analyzer. Serum sodium and potassium were determined by flame photometry using Instrumentation Laboratory Inc Model 143 Flame Photometer. Blood sugar was determined by using Technicon Auto Analyzer (Sequential Multiple Analysis 12.)

A constant infusion pump was used to inject water or $20 \%$ glucose at a rate of $0.13 \mathrm{ml} / \mathrm{Kg} / \mathrm{min}$ during induced hypoxia.

After a steady state had been attained baseline values were measured and oxygen percentage was reduced to $10 \%$ in the inspired air by diluting the air with $90 \%$ nitrogen to produce acute hypoxia. The steady infusion of water was commenced at the same time. When left ventricular contractility was depressed to $45-50 \%$ of control, blood samples were taken, and then inspired oxygen increased to $60 \%$ again.

After the animal had recovered and maintained normal parameters for an hour the experiment was repeated substituting $20 \%$ glucose infusion during acute hypoxia at an identical rate to that of water. Again when myocardial contractility was depressed to the same degree blood samples were taken for analysis for blood gases and electroytes. Statistical analysis of the results was carried using paired student's " $t$ " test taking $p=0.05$ as the limit of significance.

\section{Results}

I. Myocardial contractility, blood pressure, heart rate, and electrocardiogram during acute hypoxia

Five dogs, after the baseline hemodynamics (contractility, blood pressure, central venous pressure, and electrocardiogram) were measured, were exposed to acute hypoxia until the ventricular contractility was reduced to 45 to $50 \%$ of the control value. A representative recording from one experiment is shown in Fig. 1. The time for 50 to $55 \%$ decrease in the contractility during hypoxia was observed to be $26.8 \pm 2.05 \mathrm{~min}$ (Table I). The normal heart rate averaged $129 \pm 10 / \mathrm{min}$. Hypoxia produced a slight increase $(135 \pm$ 18) in the heart rate but the increase was insignificant (Fig. 2). The normal mean arterial blood pressure was found to be $98 \pm 4 \mathrm{mmHg}$. Hypoxia significantly decreased $(53 \pm 9 \mathrm{mmHg}$ ) the blood pressure (Fig. 2). Hypoxia produced a depression of the S-T segment in lead II electrocardiogram and this effect was consistent in all the dogs (Fig. 1). In 2 of 5 dogs extrasystole appeared during hypoxia. The mean central venous pressure in control dogs 


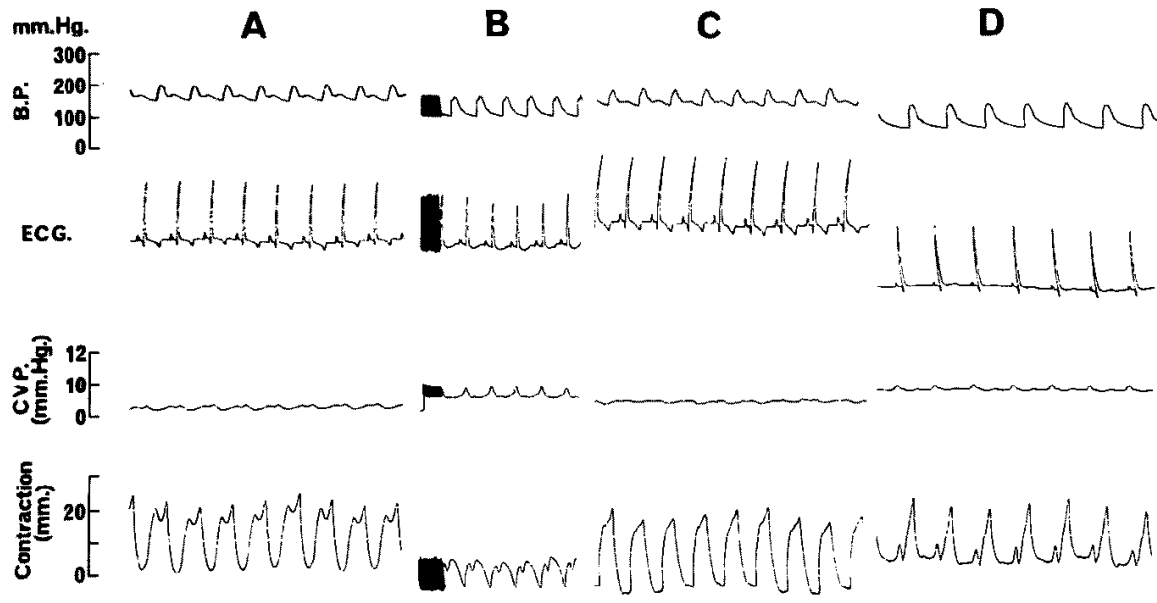

Fig. 1. Effects of hypoxia with or without glucose infusion on the simultaneously recorded arterial blood pressure, electrocardiogram (ECG), central venous pressure (CVP), and ventricular contraction in open chest anesthetized dog. Pannel A: Control, dog was ventilated with a mixture of $60 \%$ oxygen and $40 \%$ nitrogen; Pannel B: 22 min after dog was ventilated with a mixture of $10 \%$ oxygen and $90 \%$ nitrogen and water infusion; Pannel C: Second control, dog was ventilated with a gas mixture of $60 \%$ oxygen and $40 \%$ nitrogen to bring it back to control level; Pannel D: 48 min after the dog was ventilated with a gas mixture of $10 \%$ oxygen and $90 \%$ nitrogen and glucose solution was infused.

Observe a marked decrease in the blood pressure and contractility, an increase in the central venous pressure and depression of the S-T segment during hypoxia (Pannel B). Also observe the return of the blood pressure, contractility, and central venous pressure to control values (Pannel C). Observe the decrease in the blood pressure, contractility, and heart rate, and an increase in the central venous pressure after glucose infusion during hypoxia (Pannel D). Note the delaying of the effects of hypoxia on these parameters when glucose was infused.

Table I. Time for 50 to $55 \%$ Decrease in the Contractility during Hypoxia with or without Glucose Infusion in Anesthetized Open Chest Dogs

\begin{tabular}{c|cc}
\hline \multirow{2}{*}{ No. of Experiment } & \multicolumn{2}{c}{$\begin{array}{c}\text { Time in Minutes for } 50 \text { to } 55 \% \text { Decrease in } \\
\text { Contractility during Hypoxia }\end{array}$} \\
\hline 1 & $\begin{array}{c}\text { Without Glucose Perfusion } \\
\text { With Glucose Perfusion }\end{array}$ \\
2 & 20 & 27.5 \\
3 & 30 & 60.0 \\
4 & 30 & 60.0 \\
5 & 30 & 45.0 \\
Mean & 24 & 32.0 \\
\pm S.E. & 26.8 & 44.8 \\
p & 2.05 & 6.86 \\
\hline
\end{tabular}


Control

\section{Hypoxia + water infusion}

80 Control (second)

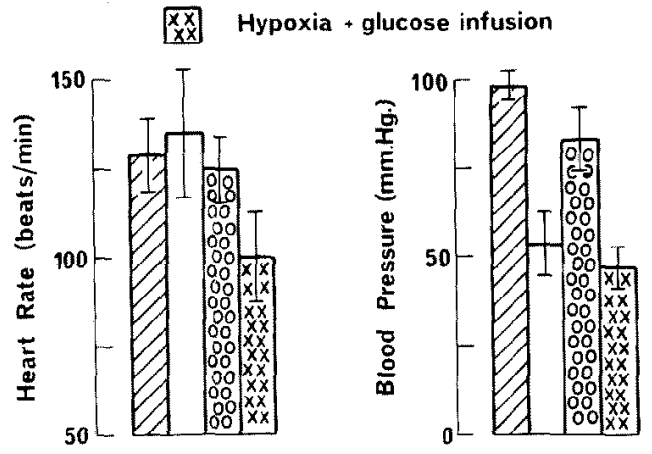

Fig. 2. Histogram showing the changes in the heart rate and blood pressure during hypoxia with or without glucose infusion in 5 anesthetized open chest dogs. Control, dogs were ventilated with a gas mixture of $60 \%$ oxygen and $40 \%$ nitrogen; hypoxia + water infusion, dogs were ventilated with a gas mixture of $10 \%$ oxygen and $90 \%$ nitrogen and water was infused at a rate given in the method; control (second), dogs were ventilated with a gas mixture of $60 \%$ oxygen and $40 \%$ nitrogen to bring them back to control level; hypoxia + glucose infusion, dogs were ventilated with a gas mixture of $10 \%$ oxygen and $90 \%$ nitrogen; and glucose solution infused at a rate described in the method section. Observe the tendency to an increase in heart rate during hypoxia without glucose infusion and a significant de* crease in the heart rate with glucose infusion. Also observe the significant fall in the blood pressure during hypoxia with or without glucose infusion.

was found to be $2.5 \pm 2 \mathrm{mmHg}$. The central venous pressure increased $(8.5 \pm$ $2 \mathrm{mmHg}$ ) during hypoxia (Fig. 1).

II. Myocardial contractility, blood pressure, heart rate, and electrocardiogram during hypoxia and glucose infusion

The above-mentioned 5 dogs that were exposed to hypoxia were ventilated with $60 \%$ oxygen in nitrogen until the hemodynamics returned to normal. One hour after the hemodynamic parameters returned to normal, the dogs were exposed to hypoxia, but this time glucose solution was infused simultaneously with hypoxia. The end point of the experiment was taken when the contractility of ventricle was reduced to 45 to $50 \%$ of the control value. A representative recording from one experiment is shown in Fig. 1. The time for 50 to $55 \%$ decrease in contractility during hypoxia with glucose infusion was $44.8 \pm 6.86 \mathrm{~min}$ (Table I). Glucose delayed the hypoxia-induced decrease in the contractility significantly. 
The heart rate had returned to normal value $(125 \pm 9 / \mathrm{min})$ before hypoxia was induced and glucose was infused in the dogs. Contrary to the effects of hypoxia alone where the heart rate had a tendency to increase, glucose infusion during hypoxia produced a decrease in the heart rate significantly (Fig. 2). The heart rate decreased to $100 \pm 13 / \mathrm{min}$ from the normal value of $125 \pm 9 / \mathrm{min}$.

The blood pressure returned to near control value $(83 \pm 9 \mathrm{mmHg})$ when the dogs were ventilated with a mixture of $60 \%$ oxygen and $40 \%$ nitrogen after they had been hypoxic for the first period. When the dogs were exposed to hypoxia and glucose infusion, the blood pressure decreased significantly. The percent decreases in the blood pressure during hypoxia with and without glucose were not significantly different, the values being 42.52 and 46.15 , respectively. Glucose delayed and in most cases prevented the appearance of S-T segment depression. In none of the dogs, ventricular ectopic beats appeared during hypoxia when glucose was infused.

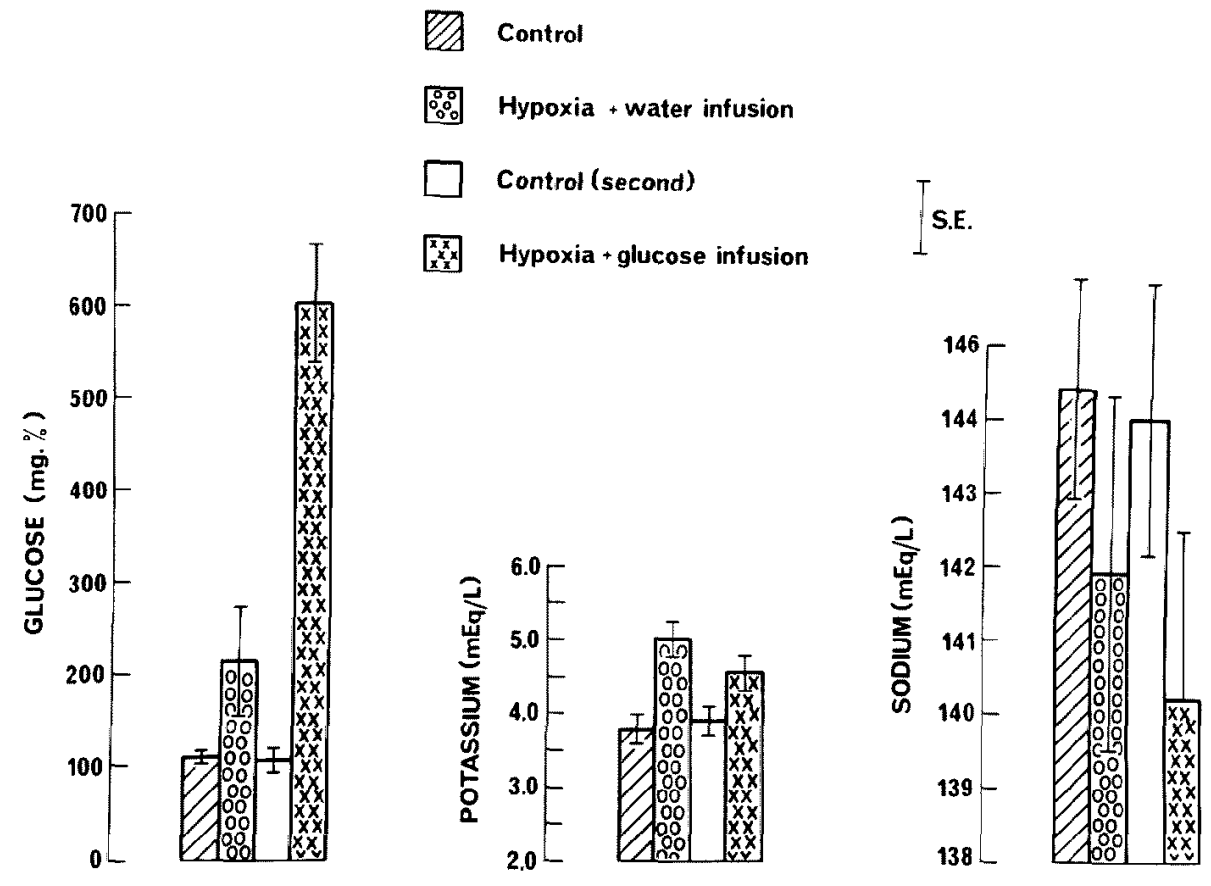

Fig. 3. Histogram showing the changes in the blood glucose, potassium and sodium in 5 dogs during hypoxia with or without glucose infusion. The notations are the same as in Fig. 2. Note the significant increase in blood glucose and potassium during hypoxia with or without glucose infusion. Observe that the increase in blood potassium during glucose infusion is less than that without glucose infusion. Note also that there was a decrease in the blood sodium. 
III. Blood electrolytes and glucose during acute hypoxia

Blood glucose, sodium, and potassium were measured in 5 dogs before and after hypoxia was induced in them. The normal values for glucose, potassium, and sodium were $112 \pm 8 \mathrm{mg} \%, 3.8 \pm 0.2 \mathrm{mEq} / \mathrm{L}$, and $144.4 \pm$ $1.5 \mathrm{mEq} / \mathrm{L}$, respectively. Hypoxia produced significant increases in the blood glucose and potassium levels, the increases being $92.8 \%$ and $31.6 \%$, respectively (Fig. 3). Although there was a decrease (1.46\%) in the level of sodium in the blood, the decrease was not significant (Fig. 3).

IV. Blood electrolytes and glucose during acute hypoxia with glucose infusion

The hypoxic dogs were ventilated with a gas mixture of $60 \%$ oxygen and $40 \%$ nitrogen to bring them back to control level, and blood electrolytes and glucose were measured. The blood glucose, potassium, and sodium levels were $108 \pm 14 \mathrm{mg} \%, 3.9 \pm 0.2 \mathrm{mEq} / \mathrm{L}$, and $144 \pm 0.85 \mathrm{mEq} / \mathrm{L}$, respectively, and these values were not significantly different from those in the control dogs. When these dogs were made hypoxic for the second time and glucose solution was infused in them at a rate mentioned in the method section, there was a significant increase in the glucose and potassium and an insignificant decrease in the sodium content of the blood (Fig. 3). The blood glucose level was found to be $604 \pm 64 \mathrm{mg} \%$ which was 5.4 times the normal value. The increase in the blood glucose during hypoxia without glucose infusion was $93 \%$ (1.93 times normal value). The percent increase in the blood potassium during hypoxia without glucose infusion was 31.5 while that during hypoxia with glucose infusion was 19.7 (Fig. 3). Glucose infusion appears to have reduced the potassium loss from the cells. The decrease in the sodium content of blood during hypoxia with glucose infusion was found to be $2.64 \%$, while that during hypoxia without glucose infusion was $1.46 \%$ (Fig, 3). These values were not significantly different.

V. Blood $\mathrm{pH}, \mathrm{Po}_{2}$, and $\mathrm{PCO}_{2}$ during hypoxia

The normal values for blood $\mathrm{pH}, \mathrm{Po}_{2}$, and $\mathrm{PCO}_{2}$ in 5 experimental dogs were $7.37,91.5 \mathrm{mmHg}$, and $26.2 \mathrm{mmHg}$, respectively (Fig. 4). Hypoxia produced significant decreases in the $\mathrm{pH}$ and $\mathrm{Po}_{2}$, the decreases being $2.2 \%$ and $76.5 \%$, respectively. Although there was a tendency for a decrease in $\mathrm{PCO}_{2}$, the change was not significant. The whole picture appears to be metabolic acidosis complicated with respiratory alkalosis.

VI. Blood $\mathrm{pH}, \mathrm{Po}_{2}$, and $\mathrm{PCO}_{2}$ during hypoxia with glucose infusion

The hypoxic dogs were then ventilated with a gas mixture of $60 \%$ 

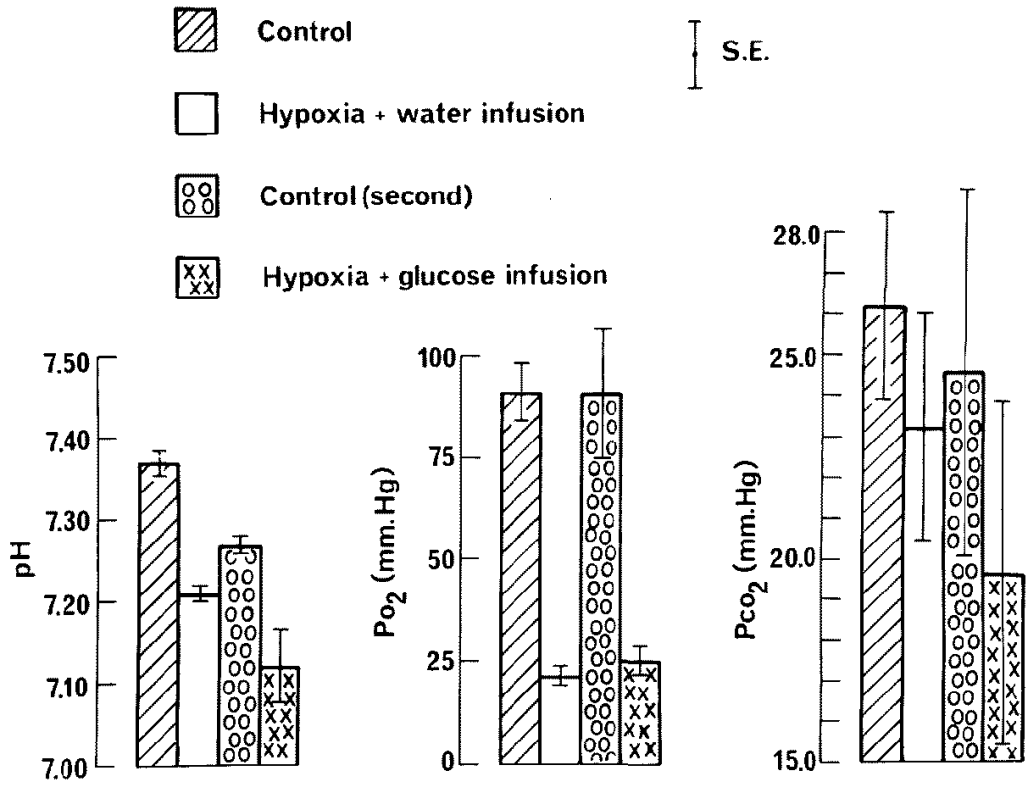

Fig. 4. Histogram showing the changes in the blood $\mathrm{pH}, \mathrm{P}_{\mathrm{O}_{2}}$, and $\mathrm{P}_{\mathrm{CO}_{2}}$ in 5 dogs during hypoxia with or without glucose infusion. The notations are the same as in Fig. 2. Observe the significant decreases in the $\mathrm{pH}$ and $\mathrm{P}_{\mathrm{O}_{2}}$ during hypoxia with or without glucose infusion. Although there was a decrease in the $\mathrm{P}_{\mathrm{CO}_{2}}$, the decrease was insignificant during hypoxia.

oxygen and $40 \%$ nitrogen, the $\mathrm{pH}, \mathrm{PCO}_{2}$, and $\mathrm{Po}_{2}$ rose to 7.27, $24.6 \mathrm{mmHg}$, and $91.5 \mathrm{mmHg}$, respectively (Fig. 4). The $\mathrm{pH}$ of the blood was significantly lower than the control. The blood $\mathrm{PCO}_{2}$ was slightly lower than the control value but the difference was insignificant. This shows that dogs still had metabolic acidosis. When these dogs were ventilated with a gas mixture of $10 \%$ oxygen and $90 \%$ nitrogen and perfused simultaneously with glucose solution, the blood $\mathrm{pH}$ and $\mathrm{PO}_{2}$ decreased significantly to 7.12 and $25 \mathrm{mmHg}$, respectively. Although there was a decrease in the $\mathrm{PcO}_{2}$, this decrease was not significant (Fig. 4). This indicates that under these conditions also the metabolic acidosis persisted.

\section{Discussion}

Hypoxia produced a decrease in the cardiac contractility and blood pressure, and an increase in the heart rate and central venous pressure in the anesthetized open chest dogs. The decrease in the contractility might be due to a decrease in the energy production during hypoxia. Hypoxia induced decrease in the contractility has been reported in the isolated myocardial tissue of guinea pig $^{5,6)}$ and man. ${ }^{7-10)}$ The decrease in the blood pressure 
might be due to a decrease in the cardiac output as a result of a decrease in the cardiac contractility, because the blood pressure is determined by cardiac output and peripheral resistance. A slight but insignificant increase in the heart rate might be reflex in nature mediated through the baroreceptors as a result of fall in the blood pressure. The increase in the central venous pressure during hypoxia might result from the decreased cardiac contractility.

Glucose infusion during hypoxia delayed the rate of decrease in the myocardial contractility and blood pressure. The time for decrease in the contractility similar to hypoxia without glucose infusion was increased by $67 \%$. Glucose also delayed the rate of increase in the central venous pressure. These effects of glucose on the contractility, blood pressure and central venous pressure are mediated through an increase in the ATP production during hypoxia as a result of increased glucose concentration in the blood. Glucose induced increase in the contractility of the isolated myocardium has been observed during hypoxia. ${ }^{n-10)}$ Increased blood level of glucose would increase the uptake of glucose by the cell, since glucose uptake in the heart is a function of extracellular glucose. ${ }^{4}$ An increased uptake of glucose will provide an increased amount of energy through glycolysis. Anoxia is known to increase glucose uptake by the heart and to stimulate certain enzymes of the glycolytic pathway of glucose metabolism. ${ }^{11}$ These factors will lead to the production of enough energy to delay the rate of decrease in the contractility during hypoxia, provided that enough glucose is present in the blood. Hypoxia induced changes in S-T segment and $\mathrm{T}$ wave were prevented by glucose infusion. Hypoxia increases the rate of repolarization and glucose prevents and abolishes the hypoxia induced increase in the rate of repolarization in cardiac muscle. ${ }^{51-10}$ Since the $S-T$ segment and $T$ wave coincides with repolarization phase of the action potential, ${ }^{14)}$ it might be that glucose affects these parameters of electrocardiogram by affecting the action potential.

Hypoxia without glucose infusion produced a significant increase in blood glucose and potassium. The increase in blood glucose during hypoxia might be the result of increased glycogenolysis in the liver and kidney. ${ }^{15)}$ The increase in the blood potassium might result from loss of potassium from the cell as a result of hypoxia. Hypoxia is known to produce a net loss of potassium in the heart muscle. ${ }^{16)}$ Hypoxia-induced decrease in the $\mathrm{pH}$ might be due to increased level of lactic acid because of increased anaerobic glycolysis.

These results suggest that glucose infusion during hypoxia might prevent or delay the deterioration of the myocardial function. It would be therefore worthwhile considering the possibility of using glucose solution in the patients in the operating room and elsewhere who risk an episode of acute hypoxia from a variety of causes. 


\section{ACKNOWLEDGEMENTS}

This work was supported by a grant from the Saskatchewan Heart Foundation. The technical assistance of Miss Susan Gilmer is gratefully acknowledged.

\section{REFERENCES}

1. Shea TM, Watson RM, Piotrowski SF, Dermksian G, Case RB: Anacrobic myocardial metabolism. Am J Physiol 203: 463, 1962

2. Brachfeld $\mathrm{N}$, Scheuer $\mathrm{J}$ : Uptake and metabolism of glucose by the ischemic myocardium. J Clin Invest 43: 1301, 1964

3. Kones RJ: Metabolism of the acutely ischemic and hypoxic heart. Critical Care Medicine 1: 321,1973

4. Morgan HE, Neely JR, Wood RE, Liebecq C, Liebermeister H, Park CR: Factors affecting glucose transport in heart muscle and erythrocytes. Fed Proc 24: 1040, 1965

5. MacLeod DP, Prasad K: Influence of glucose on the transmembrane action potential of papillary muscle 1. Effects of concentration, phlorizin and insulin, non-metabolizable sugars and stimulators of glycolysis. J Gen Physiol 53: 792, 1969

6. Prasad K, MacLeod DP: Influence of glucose on the transmembrane action potential of guinea pig papillary muscle. Mctabolic inhibitors, ouabain, $\mathrm{CaCl}_{2}$ and their interaction with glucose, sympathomimetic amines and aminophylline. Circulat Res 24: 939, 1969

7. Prasad K, Callaghan JC: Effects of glucose metabolism on the transmembrane action potential and contraction of human papillary muscle during surgical anoxia. Ann Thoracic Surg 7: 571, 1969

8. Prasad K, Callaghan JC: Influence of glucose metabolism on ouabain-induced changes in the transmembrane potential and contraction of human heart in vitro. Canad J Physiol Pharmacol 48: 801, 1970

9. Prasad K, Callaghan JC: Electrophysiologic basis of use of a polarizing solution in the treatment of myocardial infarction. Clin Pharmacol Therap 12: 666, 1971

10. Prasad K: Cardiac Metabolism and Electromechanics of Human Heart in Recent Advances in Studies of Cardiac Structure and Metabolism. ed by P Roy, University Park Press, Baltimore (in press)

11. Morgan HE, Randle PJ: Regulation of glucose uptake by muscle: III. Effects of insulin, anoxia, salicylate, 2,4 dinitrophenol on membrane transport and intracellular phosphorylation of glucose in the isolated rat heart. Biochem $\mathrm{J} \mathrm{73:573,1959}$

12. Prasad K, Desousa HH: Glucagon in the treatment of ouabain-induced cardiac arrhythmias in dogs. Cardiovasc Res 6: 333, 1972

13. Prasad K: Cardiovascular effects of ionophore, lasalocid (X537-A) in cat. Proc Internat Physiol Sci 11: 63, 1974

14. Singer DH, Lazzara R, Hoffman BF: Transmembrane potentials of cardiac cells and their ionic basis. In: The Myocardial Cell, ed by SA Briller, HL Conn Jr, University of Pennsylvania Press, Philadelphia, p73-110, 1966

15. Harper HA: Glycogenolysis in Review of Physiological Chemistry. 10th Ed, Lange Medical Publ, Los Altos, California, 197-200, 1965

16. Conn HL Jr: Effects of digitalis and hypoxia on potassium transfer and distribution in the dog heart. Am J Physiol 184: 548, 1956 